\title{
Presidential Address: A Personal View of the Past and Future Roles of the International Primatological Society in Science and Education
}

\author{
W. Richard Dukelow 1 \\ Received September 10, 1992; accepted January 7, 1993
}

Traditionally, at the conclusion of each IPS president's 4-year term, he/she reports to the membership on a subject of his choice. Often these relate to great research or conservation issues within the expertise of the president. This year, I have chosen to forgo the opportunity to discuss reproductive biology, in vitro fertilization, or even squirrel monkeys and, instead, to concentrate on what our Society has been, what it is today, and where it might go in the future. The latter is a sensitive area because your new president, Alison Jolly of Princeton University, has been hard at work already with a new team of officers to guide our progress during the next 4 years. Her plans are ambitious and worthy. I shall thus try to avoid infringing on those goals and let Dr. Jolly tell you of them at a later date.

I'm not sure when I first became aware of, and joined, the International Primatological Society. I believe it was 25 years ago. My first congress was in August 1972, in Portland, Oregon, and I have attended every Congress since them except one. The 1972 congress was interesting. As a relative newcomer to primatology, I found the diversity and quality to be very stimulating. I recall dental research presentations concerning baboons with braces on their teeth; extensive, expensive, and well-done movies by field-workers; and a presentation of gibbon locomotion by the great C. R. Carpenter. I recall, as a reproductive biologist of course, a paper of sounds during orgasm in Macaca arctoides, by Suzanne Chevalier-Skolnikoff. Little did the audience realize that this excellent scientist was later to play a leading role in the prelude to the establishment of the Martha J. Galante Primate Conservation Endowment. It was an exciting time. William Mon-

${ }^{1}$ Michigan State University, East Lansing, Michigan 48823. 
tagna, Director of the Oregon Regional Primate Research Center, was in charge of the meeting, and in his usual fashion, it was organized beautifully.

I have always felt obligated to attend business meetings of organizations to which I belong. For some strange reason, perhaps evolving from my ancient primate ancestor, I enjoy them. The business meeting in Portland was unusual, to say the least. My recollection was that a slate of officers, composed predominantly of Germans and Swiss, was proposed for the quadrennium, apparently selected by the current officers or a committee. Exception to this election procedure was raised from the floor, and immediately there was a flurry of other nominations. It was announced that no one could be a candidate unless he/she could indicate a willingness to accept the office if elected, and there was much scurrying around to find candidates who could so voice their consent. I don't know how the problem was eventually resolved; supposedly there were some behind-thescene discussions. The final result was an elected slate of officers, and the Society moved on to Japan 2 years later.

My personal involvement with the International Primatological Society began in Bangalore, India, at the VIIth Congress. Professor R. Schneider had resigned as treasurer, and Maryeva Terry had temporarily filled that position. Since I held that position with the American Society of Primatologists, and no one else apparently wanted the job, I was asked if I was willing to serve as the IPS treasurer as well. I indicated that I would and was thus elected, I believe without competition. I served in this office for 9 years, working with Ms. Terry initially and, eventually, through a long and delightful period with Herman Dienske. This period, as treasurer and subsequently as president, has afforded me the opportunity to observe participantly the activities of the Society over the past 13 years of its 26-year history.

The history of scientific societies is often difficult to reconstruct. Ours is no exception. An incoming president normally inherits boxes of files and historical material passed on from his or her predecessors. Such is not the case with the International Primatological Society. I suspect that previous presidents and general secretaries have kept their records and that they now reside in 10 to 12 offices, attics, or basements around the world. There is a problem with that. Not only is the information not available to historians, but also the keepers of the history tend to retire and pass on with the eventual loss of the information to everyone. It was to this end that, 2 years ago, Reinhold Hutz was appointed as historian of this Society to try and reconstruct some of the early historical records and participant recollections of our founders and early members.

Even the original records of meetings are incomplete. Table I illustrates information that was known about early congresses. We know, for 


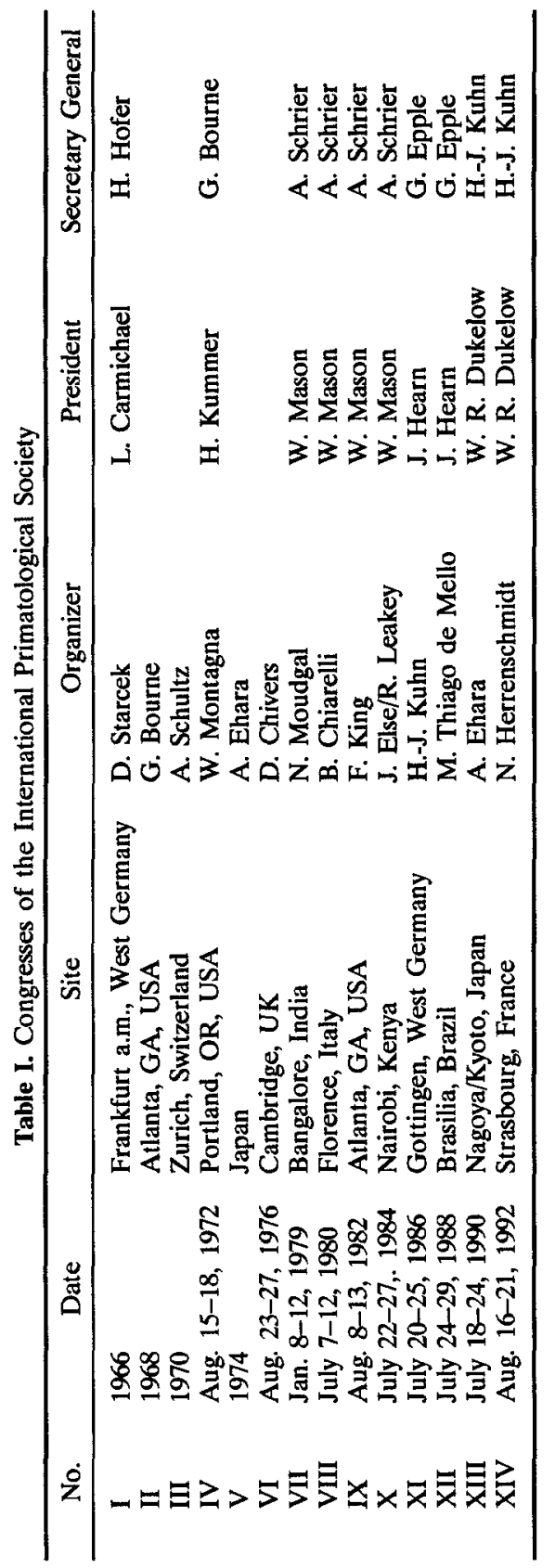


example, that the Society was organized in 1962 by Helmut Hofer and was formalized in 1964 at a meeting in Louisiana. Early officers, many of German and Swiss nationality, are not recorded in the official records. Readers who know bits of missing information are encouraged to share them with Dr. Hutz.

Neverthelesss, one can divide the activities of the International Primatological Society into three distinct eras.

The first era ran from the founding of the Society in the mid 1960s to 1980 . We cannot overestimate the efforts of our founders and the work of colleagues like Adoph Schultz, Arthur Riopelle, Helmut Hofer, Dietrich Starck, H. Preuschoff; Hans Kummer, and others who gave of their time and energies to found our society. When one tries to comprehend the enormity of establishing international congresses, publishing proceedings, and raising money to support activities in the earlier days, before Fax machines and rapid international mailings and phone calls, one can appreciate the efforts that were involved. During this era, the primary activity of the International Primatological Society was to organize and to conduct the international congress biennially. A small mimeographed newsletter was established and sent to the membership at uneven intervals. We don't know the cost of membership at the beginning of the Society, but in 1968 the fee was US $\$ 4.00$. The congresses were enthusiastically received as the new science of primatology slowly evolved. A constitution was written, in German, and roughly translated into English. No bylaws existed, and this lack, as well as flaws in the constitution, caused some problems at later meetings. All business of the Society was conducted at the international congresses, and actions taken by majority votes by members at the biennial business meetings were generally accepted as statements of the majority of the members.

The second era began in 1980, about the time of the congress in Florence, Italy. At this meeting, several significant events occurred. Officers and members became concerned that the IPS should play a larger role in conservation and captive breeding affairs. A small conservation account (US\$623), derived from small donations, had been in the treasury for several years. Funds had not been actively solicited, nor had there been a request for several years to use the funds. The general consensus was that they were not enough money to work with. At that time, the annual dues were US\$5, and by voice vote at the congress business meeting, the dues were doubled, with the additional $\$ 5$ to be designated for conservation activities. In just a few minutes, the IPS had been propelled into the conservation arena! While it was set unclear what these conservation activities would be, the stage was set and money began to be collected for conservation of our beloved primates. 
Another event of this meeting was the appearance of protestors at the congresses from various international antivivisectionist groups. We have seen them since at other IPS congresses, notably Atlanta, Georgia, in 1982 and Gottingen, Germany, in 1986. While these sometimes well-intentioned, if ill-advised, people had little overall effect, they did manage to infiltrate several scientific sessions and to volunteer to substitute for papers that were not presented.

The results of these events-increased concern for conservation, the necessity of raising funds for IPS aims, and concern over special interest groups within out society-led to recognition of the need for restructuring the IPS to provide a framework through which the Society could make major and informed contributions to the field of primatology.

The 1982 congress in Atlanta was a milestone and turning point for the Society. The IPS now had an ever-increasing conservation account, assisted by $16 \%$ interest rates on investments, and there were major discussions on how to best invest in worldwide conservation efforts. There were the expected discussions on whether money should go to training, to research programs, or to developing centers around the world and, also, what the balance should be among New World, African, and Southeast Asian species. There were further discussions on whether we had enough money to do anything, and I can recall suggesting, not without some frustration, that we use the money to buy fencing material. Fencing keeps nonhuman primates in (sometimes!) and people and other animals out (sometimes!); therefore, it might be a conservation measure on which we could all agree! My personal highlight of the meeting was the presentation made by Suzanne Chevalier-Skolnikoff from the audience during a conservation discussion. In essence, she chided us for not being more active, especially in raising funds for conservation, and she was absolutely correct! She subsequently organized efforts in the San Francisco area to raise funds for primate conservation through a "Primate Appeal." While this was technically not an IPS activity, she wanted to use the IPS for distribution of monies raised. One of the people attracted to this effort was John Galante of San Francisco, who contributed a sizable amount of money on the condition that it would be matched and used to purchase forest land in an area of Brazil that was home to several rare primate species. Dr. Chevalier-Skolnikoff also raised the matching funds from a private foundation, but due to unforseen circumstances, the Brazilian land became unavailable. Several years later, after much negotiation with Mr. Galante, these funds formed the basis for our present training endowment.

During this era there was increasing interest in our Conservation and Captive Care Committees. To spread this interest further at the congresses, the development of the conservation symposia occurred. Through the ef- 
forts of James Else and Trevor Poole, the Captive Care Committee formulated and published guidelines for the care of primates in captive situations, the only such international guidelines ever produced.

The third era of development began in the late 1980s and proceeds to the present time. It is characterized by a more formal organization of the IPS and expanded activities of the Captive Care and Breeding Committee and the Conservation Committee. Due to the problems encountered at the 1980 meetings and the increasing complexity of conservation and captive care issues, it was recognized that the IPS could not function with only biennial business meetings and that action by committees and the executive council by mail on a year-round basis was needed. This necessitated a complete revision of the IPS constitution and production of a set of bylaws. This was completed during Dr. John Hearn's term as president and with the strong and important input of Orville A. Smith. Once completed and approved by the membership, these articles allowed the executive council of the Society to transact routine business and planning by mail and telephone.

In addition, the election procedure was streamlined to allow for mail nomination and balloting. The position of president was changed to provide $\mathrm{him} / \mathrm{her}$ with a guidance and governing role within the executive council and to provide someone to speak for the Society collectively.

Respectable scientific societies normally have a journal with which to communicate societal and scientific matters, and in this era IPS formally affiliated with the International Journal of Primatology, with initial editorship by Gerald Doyle and Matt Cartmill, followed in more recent times by Russell Tuttle of Chicago.

We have always been affiliated with our representative organizations, and during this era there was an increased number of such national societies. These now include national societies from the United States, Great Britain, Japan, Brazil, Italy, France, and Australia. Others are rapidly reaching full membership size and their number will undoubtely increase. The Israeli Primate Society was an affiliated member for many years but dissolved that membership last year.

As a further sign of societal maturity, the IPS has been increasingly sought to provide advice and counsel to national organizations, governments, and businesses. Some of this was requested from outside sources; others were generated from within our Society, particularly with regard to conservation matters.

The International Guidelines for the Acquisition, Care and Breeding of Nonhuman Primates is now in a second printing and it has been widely distributed. Single copies of it are available to the members without charge from the president or the vice president for captive care and breeding. The 
Captive Care and Breeding Committee has also been charged with monitoring national regulations for primate care around the world and to encourage feasible degrees of standardization. You will soon see additional guidelines that were recently approved by the council.

Perhaps the Society's greatest contributions have come through its conservation efforts. For these, we are indebted to a recent succession of outstanding vice president's for conservation, the most recent being David Chivers of Cambridge. They not only developed effective conservation programs, but continued to serve officially or unofficially on the committee to ensure the ongoing program. One has only to view the conservation symposia of the 1992 congress to understand the effort that these dedicated people have put into our program. I express my personal appreciation to these men and women, particularly to David Chivers, for their efforts during my tenure and during earlier times.

Additionally, they have monitored conservation problems around the world and, from time to time, have recommended to the executive council that letters be written and governments encouraged to take actions to preserve our precious primates. This is a delicate task for the IPS. We must ensure that such requests are valid and fairly stated. We must ensure that data obtained are correct and unbiased. The IPS has earned the respect of governments and individuals in this regard. We must speak with scientific and intellectual accuracy, yet avoid being used by individuals or groups whose motives may be different from our own.

Earlier I mentioned the contributions of John Galante to our Society. These have been significant not only for the endowment itself, but also as a model for future efforts by IPS and its national affiliates. Mr. Galante not only gave the initial donation, but later followed it with a challenge donation that required matching funds by the Society within 4 years. Through the efforts of our American, British, and Japanese affiliates, as well as by individual donations, that goal was achieved in 2 years, shortly before our congress in Japan in 1990. That effort allowed the formal establishment of the Martha J. Galante Primate Conservation Scholarship Fund, named after Mr. Galante's wife and as a wedding present to her. This endowment, now in excess of US $\$ 42,000$ provides an annual training scholarship of approximately US $\$ 2,500-3,000$ for training of conservation fellows from habitat countries. Furthermore, under terms of the endowment, which will continue in perpetuity, there is a built-in inflation factor that will allow an increased amount and, hopefully, in the future, additional fellowships. A three-member committee annually reports to the Society whether expenditures are in accord with the original discussions with Mr. Galante. Donations are always welcome for this worthwhile endowment. 
Recipients' names are inscribed on a plaque held by the president and displayed at each meeting.

We continued to utilize US\$5 from each member's annual dues (members from developing countries are exempted from this), and this has provided an additional US $\$ 5,000$ per year for conservational activities. In recent years this money has also been utilized for conservation fellowships awarded by the Council upon recommendation of the conservation committee.

Finally, I would like to consider, in general terms, the future of the International Primatological Society.

The value of the international congresses will increase. The meetings are bigger and better with each passing biennium. As a site of international exchange of scientific information on conservation and use of nonhuman primates, there is no alternative. Not only is there personal exchange, but also our meetings in habitat countries provide excellent opportunities for members to view primates in their natural habitats and to join local primatologists to learn of their work.

The IPS will continue to play an ever-increasing advisory role to governments, businesses, and individuals regarding proper primate use and care. The expertise lies within our Society, and that is of value to others. The need for sensible, scientifically informed decisions on primates will demand this expertise. While the antivivisectionists are less active than in previous years, they will probably continue their terrorist activities, including firebombing, animal release, and death threats against those who work with primates in research and conservation efforts. These illegal activities must be terminated and the IPS must continues to take a positive stand against such illicit action.

The need for conservation training of personnel in habitat countries will increase the need for training fellowships in the future. The training of only three or four people per year is inadequate. Here the need for increased funding is evident. There is a need for stronger efforts toward financial recruiting and this must, of necessity, involve all members and all committees. Our obligation is not merely to spend money, but also to raise it.

Efforts to conserve our fellow primates will continue as the human population explosion induces further encroachment into the natural habitats of nonhuman primates. The need for intellectual exchange between members, not only through the biennial congress but also in everyday research and conservation activities, will increase, and we, as members of this Society, must meet that challenge.

Finally, I would like to thank the members of the Council, who have been so helpful over the past 4 years to make my job easier. These include 
Past President John Hearn, Secretary General Hans-Jurg Kuhn, Vice President for Conservation David Chivers, Vice President for Captive Care and Breeding Trevor B. Poole, Vice Presidents for Membership Herman Dienske and Dorothy Fragaszy, Treasurer Richard G. Rawlins, the four regional secretaries, and the presidents or appointed representatives of the affiliated national societies.

I also thank each and every member of the IPS. Over the past 13 years I have had personal contact with many of you. These contacts have been nearly always pleasant and enjoyable. I thank each of you for allowing me to work with you within this fine organization. 